\title{
Influence of Axial Involvement on Clinical Characteristics of Psoriatic Arthritis: Analysis from the Corrona Psoriatic Arthritis / Spondyloarthritis Registry
}

\author{
Philip J. Mease, Jacqueline B. Palmer, Mei Liu, Arthur Kavanaugh, Renganayaki Pandurengan, \\ Christopher T. Ritchlin, Chitra Karki, and Jeffrey D. Greenberg
}

\begin{abstract}
Objective. We analyzed the characteristics of patients with psoriatic arthritis (PsA) with and without axial involvement in the US-based Corrona Psoriatic Arthritis/Spondyloarthritis Registry.

Methods. All patients were included who had PsA and data on axial involvement, defined as physician-reported presence of spinal involvement at enrollment, and/or radiograph or magnetic resonance imaging showing sacroiliitis. Demographics, clinical measures, patient-reported outcomes, and treatment characteristics were assessed at enrollment.

Results. Of 1530 patients with PsA, 192 (12.5\%) had axial involvement and 1338 (87.5\%) did not. Subgroups were similar in sex, race, body mass index, disease duration, presence of dactylitis, and prevalence of most comorbidities. However, patients with axial involvement were younger and more likely to have enthesitis, a history of depression, and more frequently used biologics at enrollment. They were also more likely to have moderate/severe psoriasis (body surface area $\geq 3 \%, 42.5 \%$ vs $31.5 \%$ ) and significantly worse disease as measured by a lower prevalence of minimal disease activity (30.1\% vs $46.2 \%)$ and higher nail psoriasis scores [visual analog scale (VAS) 11.4 vs 6.5], enthesitis counts (5.1 vs 3.4), Bath Ankylosing Spondylitis Disease Activity Index (4.7 vs 3.5) scores, Bath Ankylosing Spondylitis Functional Index (3.8 vs 2.5) scores, C-reactive protein levels (4.1 vs 2.4 $\mathrm{mg} / \mathrm{l}$ ), and scores for physical function (Health Assessment Questionnaire, 0.9 vs 0.6), pain (VAS, 47.7 vs 36.2), and fatigue (VAS, 50.2 vs 38.6).

Conclusion. Presence of axial involvement was associated with a higher likelihood of moderate/severe psoriasis, with higher disease activity and greater effect on quality of life. These findings highlight the importance of monitoring patients with PsA for signs of axial symptoms or spinal involvement. (First Release July 1 2018; J Rheumatol 2018;45:1389-96; doi:10.3899/jrheum.171094)
\end{abstract}

Key Indexing Terms:

PSORIATIC ARTHRITIS

SPONDYLITIS

OBSERVATIONAL STUDY

PATIENT-REPORTED OUTCOME QUALITY OF LIFE

From the Swedish Medical Center and University of Washington, Seattle, Washington; Novartis Pharmaceuticals Corp., East Hanover, New Jersey, Corrona LLC, Waltham, Massachusetts; University of California San Diego, La Jolla, California; Allergy, Immunology and Rheumatology Division, University of Rochester Medical Center, Rochester; New York University School of Medicine, New York, New York, USA.

In the last 2 years, AbbVie, Amgen, BMS, Crescendo, Genentech, Horizon Pharma USA, Janssen, Eli Lilly, Novartis, Pfizer, and UCB have supported Corrona LLC, through contracted subscriptions. The study design and conduct were the result of a collaborative effort between Corrona and Novartis, and financial support for the study was provided by Novartis. Novartis participated in the interpretation of data, review, and approval of the manuscript.

J.B. Palmer is an employee of Novartis. M. Liu is an employee of Corrona LLC. R. Pandurengan and C. Karki were employees of Corrona LLC, at the time of this study. J.D. Greenberg is an employee and shareholder of Corrona LLC.

P.J. Mease, MD, Swedish Medical Center and University of Washington; J.B. Palmer, PharmD, Novartis Pharmaceuticals Corp.; M. Liu, PhD, Corrona LLC; C. Karki, MPH, Corrona LLC; A. Kavanaugh, MD,

University of California San Diego; R. Pandurengan, PhD, Corrona LLC, C.T. Ritchlin, MD, MPH, Allergy, Immunology and Rheumatology Division, University of Rochester Medical Center; J.D. Greenberg, MD, MPH, Corrona LLC, and New York University School of Medicine.
Address correspondence to Dr. P.J. Mease, Seattle Rheumatology Associates, 601 Broadway, Suite 600, Seattle, Washington 98122, USA. E-mail:pmease@philipmease.com

Full Release Article. For details see Reprints and Permissions at jrheum.org

Accepted for publication February 28, 2018.

Psoriasis is an autoimmune inflammatory disease affecting $>7$ million adults in the United States and about 2\% to 4\% of the global population ${ }^{1,2,3}$. About $30 \%$ of patients with psoriasis eventually develop psoriatic arthritis (PsA), typically described as an inflammatory disease of the skin and musculoskeletal system ${ }^{4,5,6}$. The clinical spectrum of PsA is diverse in characteristics: patients may exhibit axial skeleton disorders, nail and skin changes, peripheral joint inflammation, enthesitis, and/or dactylitis; these symptoms can be found in isolation or in combination with each other. Thus the clinical heterogeneity of this disease presents a challenge in diagnosis and treatment ${ }^{7,8}$.

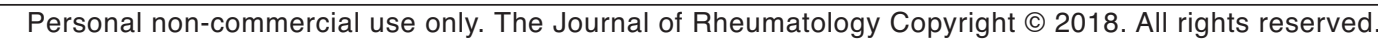


Depending on the definition used, about $25 \%$ to $75 \%$ of patients with PsA have axial involvement (axial PsA) and experience inflammatory back pain and stiffness, along with spinal involvement on imaging (e.g., sacroiliitis, spinal ossifications $)^{9}$. The definition of axial PsA has varied from unilateral advanced sacroiliitis to sharing similarities with ankylosing spondylitis (AS) ${ }^{9}$; however, axial PsA and AS differ clinically, and may be best distinguished through radiographic techniques. Axial involvement in PsA was first described $>50$ years ago, with the observation of frequent sacroiliac changes (e.g., erosion, sclerosis, and ankyloses of sacroiliac joints) in patients with PsA that were not present in controls who had rheumatoid arthritis ${ }^{10}$. In studies performed several decades ago in patients with AS, psoriasis, and other rheumatic diseases, investigators observed that compared with AS, axial PsA occurred less frequently in men, manifested as less severe spinal disease, and showed reduced association with HLA-B27; however, no difference was noted in its effects on functional capacity and quality of life ${ }^{10,11,12,13,14}$. To our knowledge, only 1 observational study has characterized PsA stratified by presence versus absence of physician-confirmed axial involvement; however, this study was conducted outside the United States and was not comprehensive, excluding analyses of detailed patient characteristics, laboratory assessments, and patient-reported outcomes ${ }^{15}$. Therefore very little is known about the effect of axial involvement on patient-reported outcomes and other assessments of quality of life.

Despite first being described $>50$ years ago, the characterization of axial PsA remains poorly understood, because limited data are available on this specific population. Current classification criteria for identification of axial spondyloarthritis (SpA) and PsA overlap between the Assessment of Spondyloarthritis international Society (ASAS) and Classification Criteria for Psoriatic Arthritis recommendations ${ }^{16,17}$. Axial PsA is accompanied by significant clinical morbidity, the treatment of which has been addressed by both the Group for Research and Assessment of Psoriasis and Psoriatic Arthritis (GRAPPA) and the European League Against Rheumatism (EULAR) ${ }^{18,19}$. The GRAPPA treatment recommendations for axial PsA are largely derived from AS literature; for patients with axial involvement, the use of nonsteroidal antiinflammatory drugs (NSAID), physiotherapy, and tumor necrosis factor inhibitors is recommended, along with conditional recommendations for the use of interleukin (IL)-17 and IL-12/23 inhibitors ${ }^{18}$. For patients with PsA with predominant active axial disease and not responding to NSAID, a biologic therapy should be initiated as per EULAR recommendations ${ }^{19}$.

Because a limited number of studies on the clinical characteristics and patient-reported outcomes of axial PsA are available, examination of the characteristics that distinguish between patients with and without axial involvement may help healthcare providers manage and improve the quality of life in patients with PsA. In this analysis, we examined the clinical and patient-reported effect of axial involvement in patients with PsA using the Corrona Psoriatic Arthritis/Spondyloarthritis (PsA/SpA) Registry.

\section{MATERIALS AND METHODS}

Study population. The Corrona PsA/SpA Registry is a large, independent, prospective observational cohort of patients with PsA or SpA. The Corrona PsA/SpA Registry database includes information about 7476 patient visits, with a mean duration of patient followup of 1.5 years. As of July 2016, data on about 2330 patients with PsA/SpA have been collected from 28 private and academic practice sites across 25 states in the United States, with 34 participating rheumatologists. Our study included all patients with PsA enrolled in the Corrona PsA/SpA Registry between March 2013 and March 2016 with available data on axial involvement, who were further stratified based on presence vs absence of axial involvement.

Patients with axial involvement were defined as those who had a physician-reported presence of spinal involvement at enrollment, based on clinical judgment of clinical features thought to be representative of active inflammatory spondylitis, and/or radiographs or magnetic resonance imaging showing sacroiliitis. Patients without axial symptoms were defined as patients with no axial involvement.

All participating investigators were required to obtain full board approval for conducting noninterventional research involving human subjects with a limited dataset. Sponsor approval and continuing review were obtained through a central independent review board (New England IRB, NEIRB No. 120160070). For academic investigative sites that did not receive a waiver to use the central IRB, full board approval was obtained from the respective governing IRB and documentation of approval was submitted to the sponsor prior to initiating any study procedures. All research was conducted in compliance with the Helsinki Declaration of 1964 and all later amendments. All registry subjects were required to provide written informed consent and authorization prior to participating

Outcomes and assessments. Data were collected using provider and patient questionnaires from treating rheumatologists and patients at twice-yearly office visits. All assessments, including demographics, clinical characteristics, patient-reported outcomes, and medication history, were collected at baseline (i.e., time of enrollment in the registry). Data were collected on demographics and patient characteristics [e.g., age, sex, race, body mass index (BMI)], disease duration, HLA-B27 positivity, history of comorbidities, family history, and prior and current medication [biologics, conventional synthetic disease-modifying antirheumatic drugs (csDMARD), and prednisone]. Clinical features [e.g., presence of enthesitis, Spondyloarthritis Research Consortium of Canada Enthesitis Index, presence of dactylitis, dactylitis counts, affected body surface area (BSA), tender (0-66) and swollen (0-68) joint counts, and nail psoriasis on a visual analog scale (VAS) from 0-100], disease activity measures [e.g., achievement of minimal disease activity (MDA $)^{20}$, Clinical Disease Activity Index, Bath Ankylosing Spondylitis Disease Activity Index (BASDAI), Bath Ankylosing Spondylitis Functional Index (BASFI), 28-joint Disease Activity Score using C-reactive protein (CRP), and Ankylosing Spondylitis Disease Activity Score using CRP (ASDAS-CRP)], and laboratory measurements (e.g., CRP and erythrocyte sedimentation rate) were assessed. MDA was defined as "yes" if a patient met 5 of the 7 following categories ${ }^{20}$ : tender joint count $\leq 1$, swollen joint count $\leq 1, \mathrm{BSA} \leq 3 \%$, patient pain $\mathrm{VAS} \leq 15$, patient global activity VAS $\leq 20$, Health Assessment Questionnaire (HAQ) score $\leq 0.5$ and tender entheseal points $\leq 1$. Lastly, patient-reported outcomes were assessed at baseline: e.g., patient-reported pain (VAS 0-100) and fatigue (VAS 0-100), morning stiffness, physical function using the HAQ, quality of life using the EQ VAS and the 3-level EQ-5D questionnaire (EQ-5D-3L), and Work Productivity and Activity Impairment (WPAI).

Statistical analysis. Descriptive analyses on patient demographics, clinical characteristics, patient-reported outcomes, and medication history were

Personal non-commercial use only. The Journal of Rheumatology Copyright @ 2018 . All rights reserved. 
conducted for all patients with PsA enrolled in Corrona at registry enrollment (baseline) and stratified by presence versus absence of axial involvement. Categorical variables (e.g., sex, race, BMI, comorbidities) were summarized using frequency counts and percentages. Continuous variables (e.g., age, clinical and disease measures) were summarized by the counts and mean (SD). Statistical comparisons between subgroups were evaluated using $t$ tests for continuous variables and chi-square tests for categorical variables. All analyses were performed using Stata V13 (StataCorp) ${ }^{21}$.

\section{RESULTS}

Patient population and baseline patient characteristics. A total of 1530 patients with PsA in the Corrona PsA/SpA Registry had available data on physician-reported axial involvement, including 192 patients (12.5\%) with axial involvement and 1338 patients $(87.5 \%)$ without axial involvement. Both subgroups were similar regarding most demographic characteristics, including sex, race, BMI, history of most comorbidities, and prior use of csDMARD and prednisone (Table 1). However, patients with axial involvement were significantly younger (50.4 vs $54.4 \mathrm{yrs}$; $\mathrm{p}<0.001)$ and were significantly more likely to have

Table 1. Baseline patient demographics and characteristics. All values were calculated based on available data and are presented as mean \pm SD or $\mathrm{n}(\%)$.

\begin{tabular}{|c|c|c|c|c|}
\hline Characteristics* & $\begin{array}{l}\text { Overall, } \\
\mathrm{n}=1530\end{array}$ & $\begin{array}{c}\text { With Axial } \\
\text { Involvement, } \mathrm{n}=192\end{array}$ & $\begin{array}{c}\text { Without Axial } \\
\text { Involvement, } \mathrm{n}=1338\end{array}$ & $\mathrm{p}$ \\
\hline Age, yrs & $53.9 \pm 13.2$ & $50.4 \pm 13.6$ & $54.4 \pm 13.1$ & $<0.001$ \\
\hline Race & & & & 0.26 \\
\hline White & $1397(94.5)$ & $170(93.9)$ & $1227(94.6)$ & \\
\hline Asian & $24(1.6)$ & $3(1.6)$ & $21(1.6)$ & \\
\hline Mixed race & $19(1.3)$ & $6(3.3)$ & $13(1.0)$ & \\
\hline Native American & $1(0.1)$ & $0(0.0)$ & $1(0.1)$ & \\
\hline Other & $10(0.7)$ & $1(0.5)$ & $9(0.7)$ & \\
\hline BMI, $\mathrm{kg} / \mathrm{m}^{2}$ & $31.4 \pm 7.2$ & $20.7 \pm 7.1$ & $31.6 \pm 7.3$ & 0.12 \\
\hline BMI (in $\mathrm{kg} / \mathrm{m}^{2}$ ) classifications & & & & 0.57 \\
\hline Normal/underweight, $<25.0$ & $239(16.5)$ & $33(18.4)$ & $206(16.2)$ & \\
\hline Patients with available HLA-B27 test re & & & & \\
\hline laboratory form) & $340(22.2)$ & $84(43.7)$ & $256(19.1)$ & \\
\hline Positive test result (among patients & & & & \\
\hline test results) & $62(18.2)$ & $20(23.8)$ & $42(16.4)$ & 0.13 \\
\hline HLA-B27+, physician-reported & $78(5.1)$ & $27(14.1)$ & $51(3.8)$ & $<0.001$ \\
\hline \multicolumn{5}{|l|}{ History of comorbidities } \\
\hline Cardiovascular disease $^{\dagger}$ & $756(49.4)$ & $93(48.4)$ & $663(49.6)$ & 0.77 \\
\hline Depression & $213(13.9)$ & $44(22.9)$ & $169(12.6)$ & $<0.001$ \\
\hline Diabetes mellitus & $206(13.5)$ & $26(13.5)$ & $180(13.5)$ & 0.97 \\
\hline Any cancer ${ }^{\ddagger}$ & $106(6.9)$ & $14(7.3)$ & $92(6.9)$ & 0.83 \\
\hline Serious infections ${ }^{\S}$ & $77(5.0)$ & $14(7.3)$ & $63(4.7)$ & 0.13 \\
\hline \multicolumn{5}{|l|}{ Prior medication use } \\
\hline Concomitant other csDMARD only & $35(2.3)$ & $6(3.1)$ & $29(2.2)$ & \\
\hline Current prednisone use & $103(6.7)$ & $9(4.7)$ & $94(7.0)$ & 0.227 \\
\hline
\end{tabular}

* All variables had $<20 \%$ missing data. ${ }^{\dagger}$ Combined histories of myocardial infarction, acute coronary syndrome, coronary artery disease, congestive heart failure, hypertension, hyperlipidemia, peripheral artery disease, cardiac revascularization procedure, ventricular arrhythmia, cardiac arrest, unstable angina, stroke, transient ischemic attack, pulmonary embolism, carotid artery disease, deep vein thrombosis, or other cardiovascular event. ${ }^{\ddagger}$ Excludes nonmelanoma of the skin. ${ }^{\S}$ Includes those infections that lead to hospitalization or intravenous antibiotics: joint/bursa, cellulitis, sinusitis, diverticulitis, sepsis, pneumonia bronchitis, gastroenteritis, meningitis, urinary tract infection, upper respiratory tract infection, or infection of other specified site. BMI: body mass index; csDMARD: conventional synthetic disease-modifying antirheumatic drug; MTX: methotrexate. 
physician-reported HLA-B27 positivity $(14.1 \%$ vs $3.8 \%$, $\mathrm{p}<0.001)$, a history of depression $(22.9 \%$ vs $12.6 \%$, $\mathrm{p}<0.001)$, and prior biologic use $(72.9 \%$ vs $59.6 \%, \mathrm{p}<0.001)$ at registry enrollment compared with patients without axial involvement.

Disease characteristics. Patients with axial involvement generally had more severe disease at registry enrollment compared with those patients without axial involvement (Table 2). Patients with axial involvement were significantly more likely to have moderate/severe psoriasis at enrollment as assessed by $\mathrm{BSA} \geq 3 \% 22(42.5 \%$ vs $31.5 \%, \mathrm{p}=0.005)$ and worse nail psoriasis $(11.4$ vs $6.5, \mathrm{p}<0.001)$. These patients had a higher likelihood of enthesitis (30.7\% vs $19.2 \%$, $\mathrm{p}<0.001)$, higher tender joint counts (5.2 vs 3.5, $\mathrm{p}=0.004$ ), and lower likelihood of MDA at enrollment $(30.1 \%$ vs $46.2 \%, \mathrm{p}<0.001)$, with significantly worse BASDAI scores (4.7 vs 3.5, p < 0.001), BASFI scores (3.8 vs $2.5, \mathrm{p}<0.001$ ), and ASDAS-CRP (2.2 vs $1.9, \mathrm{p}=0.001)$.

Patient-reported outcomes. Overall, patient-reported outcomes were significantly harmed by the presence of axial involvement (Table 3). Patients with axial involvement reported significantly worse mean pain (VAS 47.7 vs 36.2 , $\mathrm{p}<0.001$ ) and fatigue (VAS 50.2 vs $38.6, \mathrm{p}<0.001$ ), and were significantly more likely to experience $\geq 30 \mathrm{~min}$ of morning stiffness $(83.2 \%$ vs $69.3 \%, \mathrm{p}<0.001)$ at enrollment, compared with patients without axial involvement. Axial involvement was also associated with significantly impaired physical function (HAQ 0.9 vs $0.6, \mathrm{p}<0.001$ ) and quality of life (EQ VAS 65.3 vs $73.3, \mathrm{p}<0.001$ ). Work productivity and activity was significantly affected by axial involvement; patients with axial involvement reported a significantly higher percentage of work time missed $(10.0 \%$ vs $3.3 \%$, $\mathrm{p}<0.001$ ), with significantly higher percentages of impairment while working ( $29.5 \%$ vs $15.0 \%, \mathrm{p}<0.001)$, overall work impairment $(32.3 \%$ vs $16.8 \%, \mathrm{p}<0.001)$, and overall activity impairment (37.0\% vs $18.1 \%$, p < 0.001$)$. Additionally, patients with axial involvement were significantly more likely to experience any problems with walking, self-care, performing usual activities, pain/discomfort, and feelings of anxiety/depression at baseline compared with patients without axial involvement, as measured by EQ-5D-3L (all statistically significant, $\mathrm{p}<0.005$; Table 4).

\section{DISCUSSION}

In our analysis of 1530 patients with PsA enrolled in the US Corrona PsA/SpA Registry who had axial data available, $12.5 \%$ of patients exhibited axial involvement at baseline, which was associated with significantly worse disease as measured by several clinical variables, including more severe skin manifestations, more severe joint disease, more enthesitis, and worse disease activity (i.e., decreased presence of MDA and higher BASDAI scores, BASFI scores, and CRP

Table 2. Baseline clinical characteristics of patients with psoriatic arthritis stratified by presence of axial involvement. Values are mean \pm SD or $\mathrm{n}(\%)$.

\begin{tabular}{|c|c|c|c|c|}
\hline Characteristics* & $\begin{array}{l}\text { Overall, } \\
\mathrm{n}=1530\end{array}$ & $\begin{array}{c}\text { With Axial } \\
\text { Involvement, } \mathrm{n}=192\end{array}$ & $\begin{array}{c}\text { Without Axial } \\
\text { Involvement, } \mathrm{n}=1338\end{array}$ & $\mathrm{P}$ \\
\hline Enthesitis & $316(20.7)$ & $59(30.7)$ & $257(19.2)$ & $<0.001$ \\
\hline Dactylitis & $194(12.7)$ & $19(9.9)$ & $175(13.1)$ & 0.22 \\
\hline Dactylitis count, $1-20$ & $2.4 \pm 1.8$ & $3.3 \pm 2.5$ & $2.3 \pm 1.7$ & 0.08 \\
\hline BSA, $\%$ affected & $5.7 \pm 11.3$ & $6.7 \pm 12.5$ & $5.5 \pm 11.1$ & 0.19 \\
\hline Moderate disease, $\geq 3$ to $\leq 10 \%$ & $296(20.5)$ & $53(29.3)$ & $243(19.3)$ & \\
\hline Severe disease, $>10 \%$ & $178(12.3)$ & $24(13.3)$ & $154(12.2)$ & \\
\hline $\mathrm{MDA}^{\dagger}$ & $554(44.2)$ & $46(30.1)$ & $508(46.2)$ & $<0.001$ \\
\hline CDAI & $11.6 \pm 8.7$ & $12.4 \pm 9.3$ & $11.6 \pm 8.6$ & 0.25 \\
\hline Tender joint count, 68 & $3.7 \pm 7.8$ & $5.2 \pm 9.2$ & $3.5 \pm 7.5$ & 0.004 \\
\hline Swollen joint count, 66 & $2.0 \pm 4.1$ & $2.3 \pm 4.9$ & $2.0 \pm 3.9$ & 0.37 \\
\hline ASDAS-CRP & $2.0 \pm 0.8$ & $2.2 \pm 0.9$ & $1.9 \pm 0.8$ & 0.001 \\
\hline CRP, mg/l & $2.6 \pm 7.3$ & $4.1 \pm 11.2$ & $2.4 \pm 6.5$ & 0.02 \\
\hline $\mathrm{ESR}, \mathrm{mm} / \mathrm{h}$ & $15.5 \pm 16.1$ & $16.5 \pm 17.4$ & $15.4 \pm 15.9$ & 0.51 \\
\hline
\end{tabular}

\footnotetext{
* All values were calculated based on available data. All variables had $<20 \%$ missing data except for CRP $(n=934)$ and ESR $(n=926) .{ }^{\dagger}$ MDA was defined as "Yes" if a patient met $\geq 5$ of the 7 following categories ${ }^{20}$ : tender joint count $\leq 1$, swollen joint count $\leq 1$, BSA $\leq 3 \%$, patient pain VAS $\leq 15$, patient global activity VAS $\leq 20, \mathrm{HAQ} \leq 0.5$, tender entheseal points $\leq 1$. ASDAS: Ankylosing Spondylitis Disease Activity Score; BASDAI: Bath Ankylosing Spondylitis Disease Activity Index; BASFI: Bath Ankylosing Spondylitis Functional Index; BSA: body surface area; CDAI: Clinical Disease Activity Index; CRP: C-reactive protein; DAS28: 28-joint Disease Activity Score; ESR: erythrocyte sedimentation rate; HAQ: Health Assessment Questionnaire; MDA: minimal disease activity; SPARCC: Spondyloarthritis Research Consortium of Canada; VAS: visual analog scale.
}

Personal non-commercial use only. The Journal of Rheumatology Copyright $\odot$ 2018. All rights reserved. 
Table 3. Baseline patient-reported outcomes. Values are mean $\pm \mathrm{SD}$ or $\mathrm{n}(\%)$.

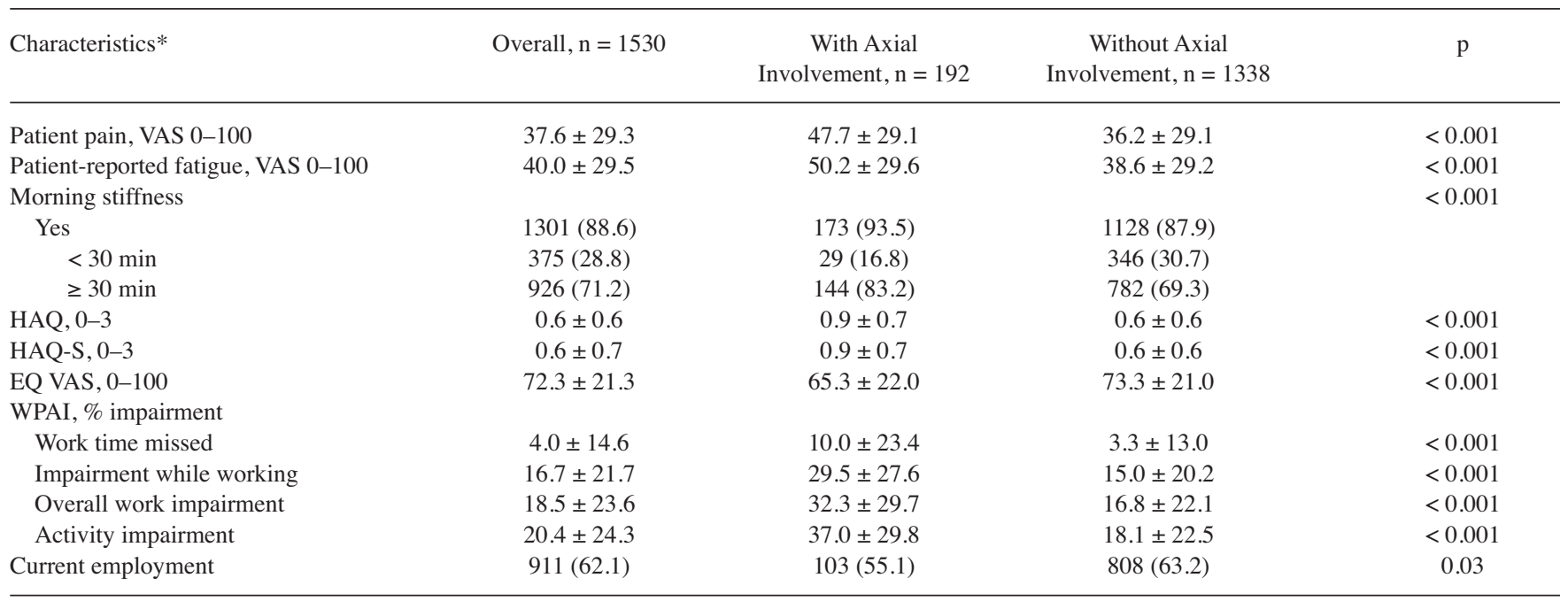

* All values were calculated based on available data. All variables had <20\% missing data except for WPAI (n, range 689-837). EQ VAS: EQ-5D visual analog scale; HAQ: Health Assessment Questionnaire; HAQ-S: HAQ for Spondyloarthropathies; VAS: visual analog scale; WPAI: Work Productivity and Activity Impairment questionnaire.

Table 4. Baseline EQ-5D-3L domains for patients with psoriatic arthritis. Values are n (\%) unless otherwise specified.

\begin{tabular}{|c|c|c|c|c|}
\hline Characteristics* & Overall, $\mathrm{n}=1530$ & $\begin{array}{c}\text { With Axial } \\
\text { Involvement, } \mathrm{n}=192\end{array}$ & $\begin{array}{c}\text { Without Axial } \\
\text { Involvement, } \mathrm{n}=1338\end{array}$ & $\mathrm{p}$ \\
\hline EQ-5D-3L index, mean \pm SD & $0.8 \pm 0.2$ & $0.7 \pm 0.2$ & $0.8 \pm 0.2$ & $<0.001$ \\
\hline No problems & $868(58.1)$ & $88(47.3)$ & $780(59.6)$ & \\
\hline Some problems & $622(41.6)$ & $97(52.2)$ & $525(40.1)$ & \\
\hline Confined to bed & $4(0.3)$ & $1(0.5)$ & $3(0.2)$ & \\
\hline Some problems washing or dressing & $258(17.8)$ & $48(27.0)$ & $210(16.5)$ & \\
\hline Unable to wash or dress self & $6(0.4)$ & $1(0.6)$ & $5(0.4)$ & \\
\hline Usual activities & & & & $<0.001$ \\
\hline No problems & $750(50.7)$ & $66(35.5)$ & $684(52.9)$ & \\
\hline Some problems & $671(45.4)$ & $107(57.5)$ & $564(43.6)$ & \\
\hline Unable to perform usual activities & $58(3.9)$ & $13(7.0)$ & $45(3.5)$ & \\
\hline Feeling anxious/depressed & & & & $<0.001$ \\
\hline Not anxious or depressed & $977(65.7)$ & $96(51.6)$ & $881(67.8)$ & \\
\hline Moderately anxious or depressed & $467(31.4)$ & $81(43.5)$ & $386(29.7)$ & \\
\hline Extremely anxious or depressed & $42(2.8)$ & $9(4.8)$ & $33(2.5)$ & \\
\hline
\end{tabular}

* All values were calculated based on available data and had < 20\% missing data. EQ-5D-3L: 3-level EQ-5D questionnaire.

levels). Patients with axial involvement were also younger and more likely to have prior biologic use, with a history of depression and a greater effect on patient-reported outcomes, physical function, and quality of life at enrollment. The prevalence of axial PsA in our study is lower than the $25 \%$ to $70 \%$ reported $^{9}$; however, other cohorts of patients with early disease/newly diagnosed PsA have reported prevalence of axial involvement (using terms such as axial arthritis, axial involvement, axial symptoms, spondylitis, and $\mathrm{SpA}$ ) in the $4.5 \%$ to $26.8 \%$ range $^{23-30}$. Further, because radiograph confirmation of axial PsA was not required, the number of patients with axial PsA may have been underestimated (asymptomatic patients with radiographic changes) or overestimated (symptomatic patients without radiographic changes). Given the general lack of consensus on the definition of axial PsA and the broad spectrum of both 
inclusion criteria and timing of patient evaluations across multiple studies, the wide range of estimates is not surprising.

Limited real-world studies exist on the characterization of axial PsA, and current classifications of this disease overlap with that of AS, thus obscuring the clinical and therapeutic implications of axial PsA. This analysis represents the first national-level query, to our knowledge, of patients with PsA from a broad geographic distribution of a primary-to-tertiary mix of clinical centers across the United States. Within a US-based registry, we have described the demographic, clinical, and treatment characteristics of patients with PsA at the time of enrollment. Data from the Corrona PsA/SpA Registry showed that in patients with PsA, presence of axial involvement was associated with significantly worse disease and widespread impairment of patient-reported outcomes at the time of registry enrollment. Patients with axial PsA also demonstrated greater overall work impairment with higher percentages of impairment across all WPAI domains compared to patients without axial involvement. Because of the lack of studies evaluating axial PsA effects on work performance, our study provides valuable information that helps to address the effects of axial PsA-related work productivity and activity loss. The findings from our present study suggest that patients with PsA who have axial involvement have more severe disease than those patients without axial involvement; however, the effect of axial involvement on progression of disease remains unclear. There have been few studies or clinical trials that have examined the progression of disease and management of patients with axial PsA $^{11,12,13,14}$. These observations are in line with another report indicating that patients with confirmed radiographic diagnosis of axial PsA failed to show improvements in back symptoms after a 10-year prospective followup, and demonstrated worsening cervical and lumbar mobility and radiographic changes over time ${ }^{31}$.

Current treatment recommendations for PsA were developed by GRAPPA based on a review of the literature and agreement between rheumatologists and dermatologists in accordance with ASAS guidelines ${ }^{18}$; accordingly, several biologics have been approved for patients with axial SpA, which may be used to inform treatment decisions for patients with axial PsA ${ }^{32-37}$. There have been only 2 observational studies that have evaluated the use of biologic therapy in patients with axial PsA ${ }^{15,38}$. A large, retrospective analysis of 1455 patients with PsA (296 with axial involvement and 1159 without axial involvement, based on clinical examination by the treating physician) in Germany demonstrated that treatment with adalimumab was effective for patients regardless of presence or absence of axial involvement ${ }^{15}$. Aside from the presence of axial involvement, the authors did not observe any obvious differences between patients with and without axial involvement at baseline; however, their analysis did not include comprehensive assessments of disease activity or patient-reported outcomes at baseline. In a 12-month observational study of patients with refractory axial PsA, treatment with etanercept led to significant improvement in BASDAI scores, suggesting that biologic therapy may be effective in patients with axial $\mathrm{PsA}^{38}$. Because of the lack of consensus on how axial PsA is identified and characterized, as well as the limited amount of data from the axial PsA patient population, many investigators have applied spinal measurements developed for use in $\mathrm{AS}$ to assess spinal mobility in $\mathrm{Ps}^{12,39}$. An examination of available radiographic scoring methods demonstrated that while some tools routinely used for axial SpA may be reliable for axial PsA (e.g., the Bath Ankylosing Spondylitis Radiology Index, the modified Stoke Ankylosing Spondylitis Spinal Score, and the Radiographic Ankylosing Spondylitis Spinal Score), the Psoriatic Arthritis Spondylitis Radiology Index, developed for axial PsA, may be superior for assessing structural damage ${ }^{40,41}$. Other metrics for assessing disease activity and inflammation in axial PsA continue to be adapted from AS, including BASDAI scores and the ASDAS ${ }^{42,43}$; however, although BASDAI scores could reliably be used in AS and peripheral PsA, these were not sufficient in evaluating axial involvement ${ }^{42}$. The lack of specific tools to assess disease activity in axial PsA highlights the need for additional data to support the development of specific and substantiated clinical tools for the appropriate monitoring and management of these patients.

As with any observational study, there are possibilities of other unmeasured confounders. The patients in our study routinely see their rheumatologists, which may not be indicative of the frequency or type of care received by the average patient. Patients were recruited by their rheumatologist, who was required to indicate diagnosis upon enrollment. Presence of axial involvement was determined based on physician diagnosis of inflammatory SpA, but imaging documentation was not required; therefore, it is possible that the proportion of patients with axial involvement may have been underestimated or overestimated.

These data highlight the need to monitor patients with PsA for axial symptoms to ameliorate disease development and progression of patient-reported measures. More formal studies in axial PsA are critical to assess specifications for diagnosis, treatment, response, and outcome measures.

\section{ACKNOWLEDGMENT}

Support for third-party writing assistance for this manuscript, furnished by Eric Deutsch, PhD, and Kheng Bekdache, PhD, of Health Interactions Inc., was provided by Novartis Pharmaceuticals Corp., East Hanover, New Jersey, USA.

\section{REFERENCES}

1. Helmick CG, Lee-Han H, Hirsch SC, Baird TL, Bartlett CL. Prevalence of psoriasis among adults in the U.S.: 2003-2006 and 2009-2010 National Health and Nutrition Examination Surveys. Am J Prev Med 2014;47:37-45.

2. Rachakonda TD, Schupp CW, Armstrong AW. Psoriasis prevalence

Personal non-commercial use only. The Journal of Rheumatology Copyright @ 2018 . All rights reserved. 
among adults in the United States. J Am Acad Dermatol 2014;70:512-6.

3. Michalek IM, Loring B, John SM. A systematic review of worldwide epidemiology of psoriasis. J Eur Acad Dermatol Venereol 2017;31:205-12.

4. Gladman DD. Clinical features and diagnostic considerations in psoriatic arthritis. Rheum Dis Clin North Am 2015;41:569-79.

5. Huynh D, Kavanaugh A. Psoriatic arthritis: current therapy and future approaches. Rheumatology 2015;54:20-8.

6. Mease PJ, Gladman DD, Papp KA, Khraishi MM, Thaçi D, Behrens $\mathrm{F}$, et al. Prevalence of rheumatologist-diagnosed psoriatic arthritis in patients with psoriasis in European/North American dermatology clinics. J Am Acad Dermatol 2013;69:729-35.

7. Gladman DD, Antoni C, Mease P, Clegg DO, Nash P. Psoriatic arthritis: epidemiology, clinical features, course, and outcome. Ann Rheum Dis 2005;64 Suppl 2:ii14-7.

8. McHugh NJ, Balachrishnan C, Jones SM. Progression of peripheral joint disease in psoriatic arthritis: a 5-yr prospective study. Rheumatology 2003;42:778-83.

9. Gladman DD. Axial disease in psoriatic arthritis. Curr Rheumatol Rep 2007;9:455-60.

10. Wright V. Psoriatic arthritis. A comparative radiographic study of rheumatoid arthritis and arthritis associated with psoriasis. Ann Rheum Dis 1961;20:123-32.

11. Helliwell PS, Hickling P, Wright V. Do the radiological changes of classic ankylosing spondylitis differ from the changes found in the spondylitis associated with inflammatory bowel disease, psoriasis, and reactive arthritis? Ann Rheum Dis 1998;57:135-40.

12. Fernandez-Sueiro JL, Willisch A, Pertega-Diaz S, Tasende JA, Fernandez-Lopez C, Galdo F, et al. Evaluation of ankylosing spondylitis spinal mobility measurements in the assessment of spinal involvement in psoriatic arthritis. Arthritis Rheum 2009;61:386-92.

13. McEwen C, DiTata D, Lingg C, Porini A, Good A, Rankin T. Ankylosing spondylitis and spondylitis accompanying ulcerative colitis, regional enteritis, psoriasis and Reiter's disease. A comparative study. Arthritis Rheum 1971;14:291-318.

14. Perez Alamino R, Maldonado Cocco JA, Citera G, Arturi P, Vazquez-Mellado J, Sampaio-Barros PD, et al; RESPONDIA Group. Differential features between primary ankylosing spondylitis and spondylitis associated with psoriasis and inflammatory bowel disease. J Rheumatol 2011;38:1656-60.

15. Behrens F, Koehm M, Arndt U, Wittig BM, Greger G, Thaci D, et al. Does concomitant methotrexate with adalimumab influence treatment outcomes in patients with psoriatic arthritis? Data from a large observational study. J Rheumatol 2016;43:632-9.

16. Rudwaleit M, van der Heijde D, Landewe R, Listing J, Akkoc N, Brandt J, et al. The development of Assessment of SpondyloArthritis international Society classification criteria for axial spondyloarthritis (part II): validation and final selection. Ann Rheum Dis 2009;68:777-83.

17. Taylor W, Gladman D, Helliwell P, Marchesoni A, Mease P, Mielants H, et al; CASPAR Study Group. Classification criteria for psoriatic arthritis: development of new criteria from a large international study. Arthritis Rheum 2006;54:2665-73.

18. Coates LC, Kavanaugh A, Mease PJ, Soriano ER, Laura Acosta-Felquer M, Armstrong AW, et al. Group for Research and Assessment of Psoriasis and Psoriatic Arthritis 2015 treatment recommendations for psoriatic arthritis. Arthritis Rheumatol 2016;68:1060-71.

19. Gossec L, Smolen JS, Ramiro S, de Wit M, Cutolo M, Dougados M, et al. European League Against Rheumatism (EULAR) recommendations for the management of psoriatic arthritis with pharmacological therapies: 2015 update. Ann Rheum Dis 2016;75:499-510
20. Coates LC, Fransen J, Helliwell PS. Defining minimal disease activity in psoriatic arthritis: a proposed objective target for treatment. Ann Rheum Dis 2010;69:48-53.

21. StataCorp. 2013. Stata statistical software: release 13. College Station, TX: StataCorp LP.

22. Van Voorhees AS, Feldman SR, Koo JY, Lebwohl MG, Menter A, Ritchlin C, et al. The psoriasis and psoriatic arthritis pocket guide - treatment algorithms and management options, 3rd ed. [Internet. Accessed May 8, 2018.] Available from: www.psoriasis.org/ pocket-guide

23. Torre Alonso JC, Rodriguez Perez A, Arribas Castrillo JM, Ballina Garcia J, Riestra Noriega JL, Lopez Larrea C. Psoriatic arthritis (PA): a clinical, immunological and radiological study of 180 patients. Br J Rheumatol 1991;30:245-50.

24. Moghaddassi M, Shahram F, Chams-Davatchi C, Najafizadeh SR, Davatchi F. Different aspects of psoriasis: analysis of 150 Iranian patients. Arch Iran Med 2009;12:279-83

25. Nossent JC, Gran JT. Epidemiological and clinical characteristics of psoriatic arthritis in northern Norway. Scand J Rheumatol 2009;38:251-5

26. Yang Q, Qu L, Tian H, Hu Y, Peng J, Yu X, et al. Prevalence and characteristics of psoriatic arthritis in Chinese patients with psoriasis. J Eur Acad Dermatol Venereol 2011;25:1409-14.

27. Coates LC, Conaghan PG, Emery P, Green MJ, Ibrahim G, MacIver $\mathrm{H}$, et al. Sensitivity and specificity of the classification of psoriatic arthritis criteria in early psoriatic arthritis. Arthritis Rheum 2012;64:3150-5.

28. Niccoli L, Nannini C, Cassara E, Kaloudi O, Susini M, Lenzetti I, et al. Frequency of iridocyclitis in patients with early psoriatic arthritis: a prospective, follow up study. Int J Rheum Dis 2012;15:414-8.

29. Papadavid E, Katsimbri P, Kapniari I, Koumaki D, Karamparpa A, Dalamaga M, et al. Prevalence of psoriatic arthritis and its correlates among patients with psoriasis in Greece: results from a large retrospective study. J Eur Acad Dermatol Venereol 2016; 30:1749-52

30. Chandran V, Tolusso DC, Cook RJ, Gladman DD. Risk factors for axial inflammatory arthritis in patients with psoriatic arthritis. J Rheumatol 2010;37:809-15

31. Chandran V, Barrett J, Schentag CT, Farewell VT, Gladman DD. Axial psoriatic arthritis: update on a longterm prospective study. J Rheumatol 2009;36:2744-50.

32. Landewe R, Braun J, Deodhar A, Dougados M, Maksymowych WP, Mease PJ, et al. Efficacy of certolizumab pegol on signs and symptoms of axial spondyloarthritis including ankylosing spondylitis: 24-week results of a double-blind randomised placebo-controlled Phase 3 study. Ann Rheum Dis 2014;73:39-47.

33. Baeten D, Sieper J, Braun J, Baraliakos X, Dougados M, Emery P, et al; MEASURE 1 Study Group; MEASURE 2 Study Group. Secukinumab, an interleukin-17A inhibitor, in ankylosing spondylitis. N Engl J Med 2015;373:2534-48.

34. Davis JC Jr, Van Der Heijde D, Braun J, Dougados M, Cush J, Clegg DO, et al; Enbrel Ankylosing Spondylitis Study Group. Recombinant human tumor necrosis factor receptor (etanercept) for treating ankylosing spondylitis: a randomized, controlled trial. Arthritis Rheum 2003;48:3230-6.

35. Inman RD, Davis JC Jr, Heijde Dv, Diekman L, Sieper J, Kim SI, et al. Efficacy and safety of golimumab in patients with ankylosing spondylitis: results of a randomized, double-blind, placebo-controlled, phase III trial. Arthritis Rheum 2008; 58:3402-12.

36. van der Heijde D, Dijkmans B, Geusens P, Sieper J, DeWoody K, Williamson P, et al; Ankylosing Spondylitis Study for the Evaluation of Recombinant Infliximab Therapy Study Group. Efficacy and safety of infliximab in patients with ankylosing

Personal non-commercial use only. The Journal of Rheumatology Copyright @ 2018 . All rights reserved 
spondylitis: results of a randomized, placebo-controlled trial (ASSERT). Arthritis Rheum 2005;52:582-91.

37. van der Heijde D, Kivitz A, Schiff MH, Sieper J, Dijkmans BA, Braun J, et al; ATLAS Study Group. Efficacy and safety of adalimumab in patients with ankylosing spondylitis: results of a multicenter, randomized, double-blind, placebo-controlled trial. Arthritis Rheum 2006;54:2136-46.

38. Lubrano E, Spadaro A, Marchesoni A, Olivieri I, Scarpa R, D'Angelo S, et al. The effectiveness of a biologic agent on axial manifestations of psoriatic arthritis. A twelve months observational study in a group of patients treated with etanercept. Clin Exp Rheumatol 2011;29:80-4.

39. Gladman DD, Inman RD, Cook RJ, van der Heijde D, Landewe RB, Braun J, et al. International spondyloarthritis interobserver reliability exercise - the INSPIRE study: I. Assessment of spinal measures. J Rheumatol 2007;34:1733-9.
40. Biagioni BJ, Gladman DD, Cook RJ, Eder L, Wakhlu A, Shen H, et al. Reliability of radiographic scoring methods in axial psoriatic arthritis. Arthritis Care Res 2014;66:1417-22.

41. Lubrano E, Marchesoni A, Olivieri I, D’Angelo S, Palazzi C, Scarpa $\mathrm{R}$, et al. The radiological assessment of axial involvement in psoriatic arthritis. J Rheumatol Suppl 2012;89:54-6.

42. Fernandez-Sueiro JL, Willisch A, Pertega-Diaz S, Tasende JA, Fernandez-Lopez JC, Villar NO, et al. Validity of the Bath Ankylosing Spondylitis Disease Activity Index for the evaluation of disease activity in axial psoriatic arthritis. Arthritis Care Res 2010;62:78-85.

43. Eder L, Chandran V, Shen H, Cook RJ, Gladman DD. Is ASDAS better than BASDAI as a measure of disease activity in axial psoriatic arthritis? Ann Rheum Dis 2010;69:2160-4. 